\title{
Adverse outcomes from reoperation after cardiac surgery: There's more to it than blood
}

\author{
Pranav R. Shah, MD, and John F. Butterworth IV, MD
}

\footnotetext{
From the Divisions of Critical Care Medicine and Cardiac Anesthesiology, Department of Anesthesiology, Virginia Commonwealth University Health System, Richmond, Va.

Disclosures: Authors have nothing to disclose with regard to commercial support.

Received for publication April 21, 2016; accepted for publication April 26, 2016; available ahead of print May 26, 2016.

Address for reprints: John F. Butterworth IV, MD, Department of Anesthesiology, VCU Health System, PO Box 980695, Richmond, VA 23298-0695 (E-mail: jfbivjbutter@yahoo.com).

J Thorac Cardiovasc Surg 2016;154:936-7

$0022-5223 / \$ 36.00$

Copyright $(2) 2016$ by The American Association for Thoracic Surgery

http://dx.doi.org/10.1016/j.jtcvs.2016.04.079
}

Despite antifibrinolytic drugs and improved medical management of coagulopathy, bleeding sufficient to require reexploration after cardiac surgery continues to occur. But, which leads to adverse outcomes: bleeding or reexploration? Ruel and colleagues ${ }^{1}$ provide valuable insights regarding the consequences of reexploration in their single-institution observational study of approximately 17,000 patients. A key finding from their study was that in-hospital mortality increased from $2.8 \%$ to $12 \%$ among patients requiring reexploration, greater than would be expected using standard risk adjustment. Reexploration also was associated with an increased likelihood of surgical site infection, intensive care unit (ICU) readmission, postoperative atrial fibrillation, and renal insufficiency, and with increased ICU and hospital lengths of stay.

Ruel and colleagues ${ }^{1}$ provide several interesting insights. Many of us would assume that worse outcomes associated with reexploration arise from its association with blood loss and blood transfusion. Of note, the authors found that reexploration was independently associated (odds ratio [OR], 3.4) with mortality, even with adjustment for blood product administration (OR, 1.02 per unit) in a multivariable model. This is robust evidence that the negative impact of reexploration on mortality and morbidity cannot be blamed on the ill effects of blood transfusions alone.

The authors ${ }^{1}$ confirmed previous findings that urgent or emergency surgery increases the likelihood of reexploration $^{2-4}$ and that delayed reexploration worsens outcomes. $^{4}$ Of the $4.2 \%$ individuals requiring reexploration, $54.2 \%$ underwent reexploration on the day of surgery. These patients had an OR of $2.0(P<.001)$ for mortality, compared with $6.4(P<.001)$ for those undergoing later reexplorations.

We were intrigued by the authors' findings ${ }^{1}$ that tricuspid valve repair was associated with both reexploration (OR, 2.6; $P<.001)$ and mortality (OR, 1.9; $P=.001)$. Because

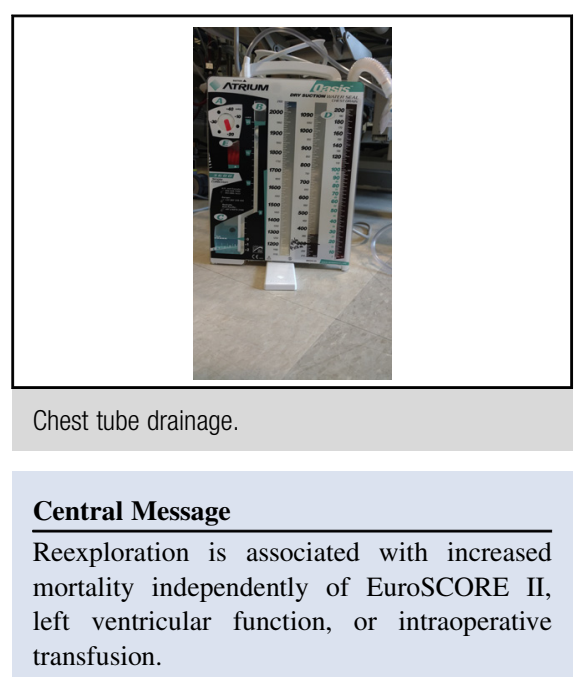

See Article page 927

tricuspid repair often is done in patients with impaired right ventricular function, perhaps right ventricular dysfunction and venous congestion increase the bleeding and detrimentally affect postoperative course.

There are several limitations worth mentioning. First, observational studies provide evidence for association, not for causation. Second, given that all these data arose from a single center, we are unable to assess the extent to which their specific practice patterns (eg, their threshold for reexploration) have influenced the findings. Third, factors associated with reexploration were not always modifiable. Fourth, they were not able to test for an association between shock due to hypoperfusion (from postoperative bleeding) and outcomes. Finally, the statistical analysis did not address the likely contributions from anticoagulants administered before surgery.

Ruel and colleagues ${ }^{1}$ provide valuable insights into the impact of reexploration after cardiac surgery and strong evidence that reexploration, aside from any associated transfusions, itself may affect outcomes. Nevertheless, the decision often is vexing as to whether to manage continuing, moderate postoperative bleeding in the ICU with transfusion or to transport the patient to the surgical theatre for reexploration. We hope that future studies can help us better decide when the risks of reexploration, as identified by Ruel and colleagues, ${ }^{1}$ are exceeded by the risks of watching and waiting. 


\section{References}

1. Ruel M, Chan V, Boodhwani M, McDonald B, Ni X, Gill G, et al. How detrimental is re-exploration for bleeding after cardiac surgery? J Thorac Cardiovasc Surg. 2017; $154: 927-35$.

2. Biancari F, Mikkola R, Heikkinen J, Lahtinen J, Airaksinen KEJ, Juvonen T. Estimating the risk of complications related to re-exploration for bleeding after adult cardiac surgery: a systematic review and meta-analysis. Eur J Cardiothorac Surg. 2012;41:50-5.

3. Mehta RH, Sheng S, O'Brien SM, Grover FL, Gammie JS, Ferguson TB, et al. Reoperation for bleeding in patients undergoing coronary artery bypass surgery: incidence, risk factors, time trends, and outcomes. Circ Cardiovasc Qual Outcomes. 2009;2:583-90.

4. Karthik S, Grayson AD, McCarron EE, Pullan DM, Desmond MJ. Reexploration for bleeding after coronary artery bypass surgery: risk factors, outcomes, and the effect of time delay. Ann Thorac Surg. 2004;78:527-34. 